\title{
Nutrient Analysis of Soil and Soilless Strawberries and Raspberries Grown in a Greenhouse
}

\author{
Chenin Treftz, Stanley T. Omaye \\ Agriculture, Nutrition and Veterinary Sciences Department and Environmental Sciences and Health Graduate \\ Program, University of Nevada, Reno, USA \\ Email: omaye@unr.edu, chenin.treftz@gmail.com
}

Received 8 May 2015; accepted 21 June 2015; published 24 June 2015

Copyright (C) 2015 by authors and Scientific Research Publishing Inc.

This work is licensed under the Creative Commons Attribution International License (CC BY).

http://creativecommons.org/licenses/by/4.0/

c) (i)

Open Access

\begin{abstract}
Soilless (hydroponic) vegetables and fruits grown in greenhouses are gaining popularity and potentially represent a compliment toward sustainable food sources. Only a few studies have looked at the nutrient quality of strawberries (Fragaria $\times$ ananassa) and raspberries (Rubus idaeus) grown in soilless systems. Dry weights, content of ascorbic acid, tocopherol, total polyphenolic compounds, glucose, fructose, and soluble solids (BRIX) of strawberries and raspberries grown in soilless systems were compared to their counterpart grown in soil. There was no change in dry weights but BRIX values $(28 \%-31 \%)$, glucose $(158 \%-175 \%)$, and fructose $(75 \%-102 \%)$ content for strawberries and raspberries respectively were significantly higher for the soil grown berries compared to soilless grown berries. Contents of ascorbic acid, tocopherol and total polyphenolic compounds were significantly higher in soilless grown strawberries compared to soil grown strawberries by $74 \%, 53 \%$, and $22 \%$ respectively, and contents of ascorbic acid and total polyphenolic compounds were significantly higher in soil grown raspberries by $83 \%$ and $67 \%$ respectively compared to soilless grown raspberries. Soilless grown produce warrants future research to strive toward the potential to provide nutrient dense crops and opportunities toward optimized sustainable production.
\end{abstract}

\section{Keywords}

Soilless, Greenhouse, Bioactive Compounds, Strawberry, Raspberry

\section{Introduction}

The United States Department of Agriculture estimates that 23 million people live in food deserts with inade- 
quate access to healthy, affordable and fresh food [1]. Inadequate access to food, especially fresh fruits and vegetables, is a public health concern because the consumption of fruits and vegetables is associated with a decreased risk of certain chronic diseases such as cardiovascular disease, type 2 diabetes, obesity and certain types of cancer [2] [3]. Growing fresh produce in soilless systems may be a potential solution to food insecurity issues regardless of soil quality, climate or space [4]. Additionally, soilless growing systems can provide several other environmental benefits such as reduction of water, increased product yields, and less pesticide use. These advantages allow soilless systems to address several environmental issues while providing sustainable systems in food deserts, in arid or urban regions.

Recently, several studies have focused on the nutritional content of soilless produce. As soilless food production grows in popularity, researching the nutritional composition of soilless compared to traditional farming methods will be important because nutrition is one of the main drivers of purchasing and consumption [5]. Some studies indicate that soilless systems provide superior nutrition compared to traditionally grown produce [6]-[9], while others indicate that no difference or soil grown produce is higher in selected nutritional parameters [10] [11]. The majority of previous research has focused primarily on lettuce, leafy greens and tomato fruit. Additionally, several of the previous studies have limitations on the findings because the comparison was conducted with produce grown in different environments known to affect bioactive compound production in the plant [12] [13]. The comparison of soilless and soil systems must occur in identical environments [14].

Limited research is available on soilless strawberries and raspberries. The aim of this study was to compare the differences in nutritional quality, as defined by bioactive compounds, Brix and moisture content of strawberries and raspberries grown in soil and soilless conditions. Strawberries (Fragaria $\times$ ananassa) and raspberries (Rubus idaeus) are a rich source of bioactive compounds and can provide a plethora of health benefits to the consumer [15]-[17].

We chose to analyze ascorbic acid, $\alpha$-tocopherol and total polyphenolics because of their role in antioxidant protection [17]-[19]. Glucose and fructose were analyzed because these two nutrients are the primary sources of sugars in strawberries and raspberries [20]. Research on sugar content is necessary since it can affect the taste of the fruit as well as consumer preferences [21]. We analyzed moisture content and Brix in the fruit, which is an important quality indicator that can influence the texture and flavor of a fruit, as well as shelf life [22].

\section{Methods}

\subsection{Chemicals}

Thiourea, copper sulfate, and orthophosphoric acid (85\%) were purchased from Fischer Scientific (Fair Lawn, NJ). Sulfuric acid, trichloroacedic acid, 2,4-dinitrophenylhydrazine, L-ascorbic acid, ferric chloride, xylene, 4,7diphenyl-1,10-phanthroline (bathophenanthroline), $( \pm) \alpha$-tocopherol, sodium carbonate, Folin-Ciocalteu, tryptaminehypochloride, hydrochloric acid $(\mathrm{HCl})$, fructose, dinitrosalcylic acid, sodium hydroxide, $\mathrm{D}(+)$-glucose, potassium sodium tartrate, and sodium sulfite were purchased from Sigma-Aldrich Cooperation (St. Louis, MO). ACS/NSP grade (200 proof) absolute ethanol was purchased from pharmco-AAPER, Kentucky.

\subsection{Growing Conditions and Plants}

Bare root strawberries and raspberries were ordered from Stark Brothers Nurseries \& Orchard Company (Louisiana, MO). In both soilless and soil plants, they were planted on the same day in late Winter 2014. Plants were grown at the University of Nevada, Reno (UNR) Experimental Station. Throughout the growing season, the greenhouse temperature was maintained at $70^{\circ} \mathrm{F}(5: 30 \mathrm{AM}$ to $6: 30 \mathrm{PM})$ during the day and $60^{\circ} \mathrm{F}(6: 31 \mathrm{PM}$ to 5:29 AM) at night with a relative humidity averaging at 30\%. Soil and soilless buckets were numbered and randomized with the available space in the greenhouse at the UNR Experimental Station. The strawberries were placed in 8 rows between two tables, and the raspberry barrels were placed on cinder blocks (Reno, NV), in 3 rows of 4 barrels.

\subsubsection{Strawberries}

Thirty bare root Ozark Beauty (Fragaria $\times$ ananassa) strawberry plants were planted in soil conditions grown in three-gallon nursery pots. Berries were planted in Nevada topsoil mixed with Miracle-Gro potting soil (Maryville, $\mathrm{OH}$ ) in a 1:1 ratio. The plants were watered by a drip irrigation system for 15 minutes, three times weekly. 
The plants were fertilized with all-purpose Miracle-Gro fertilizer every six weeks. The $\mathrm{pH}$ and parts per million (ppm) of the soil plants was measured with a portable meter before planting and quarterly, averaging at 5.6 and 400 ppm (Oakton Instruments, Vernon Hills, IL).

Thirty bare root strawberry plants were planted in soilless systems. The berries were planted in a bucket system using five-gallon paint buckets from a local hardware store (Reno, NV). The buckets were spray painted black to minimize algae growth. Hydroton, 8-inch netting, a Waterfarm ${ }^{\circledR}$ system pumping column and drip ring for construction of the bucket system was purchased from a local hydroponics store in Reno, Nevada. The plants were aerated using an all-purpose pump (Active Aqua AAPA 15L, Reno, NV). The $\mathrm{pH}$ of the plants was maintained between 6.0 - 6.4. The nutrient solution was a commercial General Hydroponics Flora Series, consisting of FloraBloom, FloraGrow and FloraMicro (Sebastopol, CA). Throughout the growing season, the nutrient ratios were changed to match the plant development, as indicated by the manufacturer instructions. The ppm averaged at 400 . The $\mathrm{pH}$ and ppm were monitored and adjusted three times weekly.

\subsubsection{Raspberries}

Six bare root Heritage (Rubus idaeus) raspberries were planted in 50 gallon barrels. A combination of Nevada topsoil was mixed with Miracle-Gro potting soil in a 1:1 ratio. The berries were watered one to three times weekly for 15 minutes with a drip irrigation system. The plants were fertilized with all-purpose Miracle-Gro fertilizer every six weeks. The $\mathrm{pH}$ and ppm of the soil was checked before planting and quarterly, averaging a $\mathrm{pH}$ of 5.6 and ppm averaging at 600 .

Six bare root Heritage varieties of raspberries were planted in 19 gallon buckets (United Solutions, TU0014, Reno, NV) using hydroton as the growing medium. Holes were drilled at the bottom of the buckets and were placed on top of the empty fifty-gallon barrel to create a large-scale version of a bucket system described with the strawberries. From the 50 gallon barrel, the water drains into a large water reservoir where a water pump distributes the water to the six soilless buckets via polyvinyl chloride (PVC) and drip tubing (Reno, NV). The water in the reservoir was maintained at a pH between 5.8 - 6.2. This $\mathrm{pH}$ was monitored and adjusted if needed three times weekly. The nutrients added to the berries were FloraGrow, FloraBloom and FloraMicro and maintained averaging at $500 \mathrm{ppm}$.

To support the berries, a T-hedgerow system was built with string and PVC pipe. A T-hedgerow system has been shown to have a comparable yield compared to the V-trellis system.

\subsubsection{Harvesting Strawberries and Raspberries}

The berries were harvested promptly when they visually reached $100 \%$ surface red color. The fruit was harvested between $7 \mathrm{AM}$ and $8 \mathrm{AM}$ for consistency, placed in a plastic laboratory bag, and immediately brought in a $-70^{\circ} \mathrm{C}$ Thermo Scientific ${ }^{\mathrm{TM}}$ Revco $^{\mathrm{TM}}$ high performance lab freezer (Thermo Fisher Scientific, Waltham, MA). The berries were stored in the freezer until analysis. All berries analyzed for comparisons were harvested on the same day. Nutrients with time sensitive oxidative properties were analyzed within thirty days of harvest, and others (i.e., glucose, fructose) were analyzed within sixty days of harvest.

\subsection{Sample Preparation}

Samples were randomly selected for analysis by hand. Before analysis, berries were rinsed with deionized water, dried with a paper towel and the stems were manually removed. For all assays, samples were homogenized using a Brinkmann Instruments Polytron homogenizer (Kinematica, Bohemia, NY).

\subsection{Brix and Moisture Content}

Brix, or soluble solids, is a common measurement of total dissolved solids in the juice, wine and soft drink industry, and can be used to approximate total sugar content. An automated digital refractometer (Milwaukee MA871, Rocky Mount, NC) was used. Procedures have been described previously [23]. Briefly, 10 grams (g) of berry samples were homogenized with a pestle and mortar. A double-dilution with an equal part by weight of distilled water was added to the homogenized berries. The berries were filtered using cheesecloth to remove seeds and pulp. After the samples were filtered, $1000 \mu \mathrm{L}$ was extracted and the results were read in triplicate.

Moisture content in fruit was estimated by using a modified version of the Official Methods of Analysis of AOAC 934.06 for moisture in dried fruit [24]. The protocols' drying portion was lengthened to 20 hours to ac- 
count for higher moisture content in fresh fruit compared to dried fruit. Briefly, three $10 \mathrm{~g}$ portions of samples were taken and homogenized with a pestle and mortar. The samples were placed in a Lab Line incubator, model 120 (Kerala, India) for 20 hours at $140^{\circ} \mathrm{F}$. After drying, the moisture content can be expressed as a percentage of mass determined by the following equation:

$$
W=\frac{M_{1}-M_{2}}{M_{1}-M_{0}} \times 100
$$

where $W$ is the moisture content, $M_{0}$ is the mass of the weight dish, $M_{1}$ is the mass of the dish and sample before drying, and $M_{2}$ is the mass of the dish and the test portion after drying.

\subsection{Ascorbic Acid Analysis}

Ascorbic acid content was determined using a modified protocol from measuring ascorbic acid in animal tissues [25]. Ten grams of berries were randomly selected and homogenized with $10 \mathrm{~mL}$ cold $20 \%$ Trichloroacetic acid (TCA). This mixture was placed into a flask wrapped in aluminum foil with 0.1 grams of activated carbon to remove color intensity and agitated for 15 minutes, and then was allowed to sit overnight [26]. The mixture was then filtered using Whatman no. 2 filter paper. A stock solution was created using L-ascorbic acid and standards were made using 5\% TCA with a serial dilution of $0-120 \mu \mathrm{g} / \mathrm{mL}$. After filtering, $100 \mu \mathrm{L}$ of the liquid was removed and added to new test tubes containing $900 \mu \mathrm{L}$ of $20 \%$ TCA. One $\mathrm{mL}$ of a mixture of 2,4-dinitrophenylhydrazine (DNPH), thiourea, copper in the presence of sulfuric acid was added to all samples, standards and blank. The copper in the solution oxidized the ascorbic acid to dehydroascorbic acid. The DNPH, thiourea and the sulfuric acid yielded a colored product with minimal interference from other chromogens. The samples, standards and blank was incubated in a $20 \mathrm{~L}$ Fischer Water Bath (Fischer Scientific, New Lawn, NJ) at $37^{\circ} \mathrm{C}$ for three hours. After incubation, $1.5 \mathrm{~mL}$ of cold $65 \%$ sulfuric acid was added to the samples, standards and blank, and a 30 minute waiting period was observed at $25^{\circ} \mathrm{C}$ to allow the color to stabilize. The absorbance of the samples, standards and blank were read at $520 \mathrm{~nm}$ with a 110 voltage FinstrumentsMicroplate Reader (Model 314, McLean, VA) in triplicate. The samples were compared to a linear regression created from the known standards $\left(y=0.0102 x+0.0316, R^{2}=0.9957\right)$. The reproducibility was measured by adding a known amount of a standard to a sample and determining the recovery, which was $110 \% \pm 2.1 \%$ [27].

\subsection{Tocopherol Analysis}

Alpha-tocopherol ( $\alpha$-tocopherol) method was derived from Fabinek et al., 1968, using Fe(III)-bathophenanthroline spectrophotometry [28]. Ten grams of berries were randomly selected for analysis and homogenized with $10 \mathrm{~mL}$ of absolute ethanol. Xylene $(1.2 \mathrm{~mL})$ was added to extract the tocopherols from the samples. The samples were then centrifuged for 20 minutes at $3500 \mathrm{rpm}$ in a Sorvall RT6000B refrigerated centrifuge at $7^{\circ} \mathrm{C}$. After centrifugation, $100 \mu \mathrm{L}$ of the organic layer was removed and was added to new test tubes containing $0.4 \mathrm{~mL}$ of bathophanthroline. Ferric chloride $(0.4 \mathrm{~mL})$ was then added to the tubes and $0.4 \mathrm{~mL}$ of orthophorsphic acid (85\%) was then added to these test tubes to stabilize the color. In similar fashion, standards were made using a serial dilution between $0-50 \mu \mathrm{g} / \mathrm{mL}$ to create a linear regression to estimate $\alpha$-tocopherol content in the samples $\left(y=0.0081 x-0.0053, R^{2}=0.9927\right)$. All samples, standards, and blank were read at $530 \mathrm{~nm}$ in triplicate with a 110 voltage FinstrumentsMicroplate Reader (Model 314, McLean, VA). The reproducibility was measured by adding a known amount of a standard to a sample and determining the recovery, which was $95 \% \pm 2.5 \%$ [6].

\subsection{Total Polyphenolics}

Total polyphenolics were determined by using the Folin-Ciocalteu assay. This method has been used in measuring the total reducing capacity in berries by gallic acid equivalents (GAE) [17] [29] [30]. Raspberries (10 g) were homogenized with $10 \mathrm{~mL}$ of ethanol. A volume of $1.58 \mathrm{~mL}$ of deionized water was added to all samples along with $100 \mu \mathrm{L}$ of the Folin-Ciocalteu reagent. A series of standards were made using the same method ranging from 0 - $300 \mathrm{mg} \mathrm{GAE/L.} \mathrm{The} \mathrm{solutions} \mathrm{were} \mathrm{allowed} \mathrm{to} \mathrm{sit} \mathrm{for} \mathrm{one} \mathrm{minute} \mathrm{and} \mathrm{then} \mathrm{mixed} \mathrm{thoroughly.}$ A volume of $300 \mu \mathrm{L}$ of $25 \%$ sodium carbonate solution was added to the samples, standards and blank and was placed into a $40^{\circ} \mathrm{C} 20 \mathrm{~L}$ Fischer Water Bath (Fischer Scientific, New Lawn, NJ) for 15 minutes and recorded in triplicate at $690 \mathrm{~nm}$ against a $0 \mathrm{GAE} \mathrm{mg} / \mathrm{L}$ solution FinstrumentsMicroplate Reader, 110 voltage (Model 314, 
McLean, VA). The GAE in the samples was estimated using the linear regression line created from the standards $\left(y=0.0021 x-0.0099, R^{2}=0.9988\right)$.

\subsection{Fructose}

Ten grams of samples were homogenized with $10 \mathrm{~mL}$ of deionized water. Samples were then centrifuged for 15 minutes at $3500 \mathrm{rpm}$ in a Sorvall RT6000B centrifuge. Into new test tubes, $100 \mu \mathrm{L}$ of the supernatant was extracted and $100 \mu \mathrm{L}$ of a tryptamine reagent (concentration of $10 \mathrm{mM}$ tryptaminehypochloride in $0.1 \mathrm{M} \mathrm{HCl}$ ) was added to each test tube along with $3 \mathrm{~mL} \mathrm{36 \%} \mathrm{HCl}$. For the standards, a series of fructose solutions were made using serial dilutions ranging from 0 to $1000 \mu \mathrm{g} / \mathrm{mL}$. All samples and standards were then placed in a $60^{\circ} \mathrm{C}$ water bath for 15 minutes. The samples and standards were then allowed to stand for forty minutes and then the absorbance was read at $520 \mathrm{~nm}$ with FinstrumentsMicroplate Reader, 110 voltage (Model 314, McLean, VA) in triplicate using deionized water as the blank [31]. Fructose was determined from the calibration curve created from the standards $\left(\mathrm{y}=0.0008 \mathrm{x}-0.0525, \mathrm{R}^{2}=0.98528\right)$.

\subsection{Glucose}

Glucose was estimated from the reducing sugars assay developed by Miller et al. [32]. Ten grams of berries were homogenized with $10 \mathrm{~mL}$ of deionized water. Samples were centrifuged for 15 minutes at $3500 \mathrm{rpm}$ in a Sorvall RT6000B centrifuge. Dinitrosalicylic acid, sodium sulfite, and sodium hydroxide were combined to make the $1 \%$ dinitroslicylic acid reagent solution [32]. A series of standards using a serial dilution were made with glucose with concentrations ranging $0-1000 \mu \mathrm{g} / \mathrm{mL}$. All samples, standards and blank were heated in a $90^{\circ} \mathrm{C}$ water bath for 15 minutes to yield a red-brown color. After heating, $300 \mu \mathrm{L}$ of $40 \%$ potassium sodium tartrate solution was added to all samples, standards and blanks to stabilize the color. The solutions were allowed to stand at room temperature for 30 minutes and then the absorbance was read at $560 \mathrm{~nm}$ with a FinstrumentsMicroplate Reader, 110 voltage (Model 314, McLean, VA) in triplicate. Glucose concentration was determined from the linear regression created from the standards $\left(y=0.0006 x-0.0315, R^{2}=0.9923\right)$.

\subsection{Statistical Analysis}

Statistical analysis was conducted with Graph Pad Prism Version 6.0f. The independent t-test was used to determine differences in soilless and soil grown berries, with a significance level set at $\mathrm{p}<0.05$. Results are expressed as mean \pm standard deviation (SD).

\section{Results}

\subsection{Brix and \% Moisture}

The results for the moisture content and Brix are shown in Table 1 and illustrated in Figure 1 and Figure 2. Both the soil strawberries and raspberries had a significantly higher Brix value compared to the soilless strawberries and raspberries. The soil grown strawberry had a Brix value $28 \%$ higher compared to the soilless strawberry. The raspberry grown in soil had a Brix value $31 \%$ higher than the soilless raspberry. There were no significant differences between the percent moisture content between soilless strawberries and raspberries.

Table 1. Brix measurement and \% moisture content (mg/100g) of soil and soilless berries (mean \pm SD).

\begin{tabular}{|c|c|c|c|c|}
\hline & Soilless Strawberries & Soil Strawberries & $\mathrm{t}$ & $\mathrm{p}$ \\
\hline Brix & $7.5 \pm 0.18$ & $9.6 \pm 0.23$ & 7.09 & $<0.0001$ \\
\hline \multirow[t]{2}{*}{ \% Moisture } & $90.74 \pm 1.06$ & $89.3 \pm 0.88$ & 1.05 & 0.34 \\
\hline & Soilless Raspberries & Soil Raspberries & $\mathrm{t}$ & $\mathrm{p}$ \\
\hline Brix & $11.7 \pm 0.47$ & $8.9 \pm 0.25$ & 5.28 & $<0.0001$ \\
\hline \% Moisture & $86.4 \pm 0.61$ & $85.8 \pm 0.98$ & 0.55 & 0.61 \\
\hline
\end{tabular}

$\mathrm{N}=3$ with 3 replicates. 


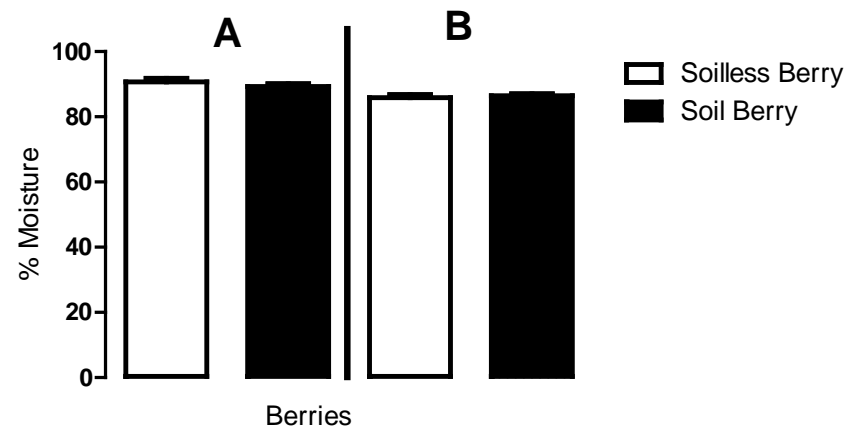

Figure 1. Percent moisture. (A) Indicates soil-grown and soillessgrown strawberries; (B) Indicates soil-grown and soilless-grown raspberries. Star $(*)$ indicates significant differences.

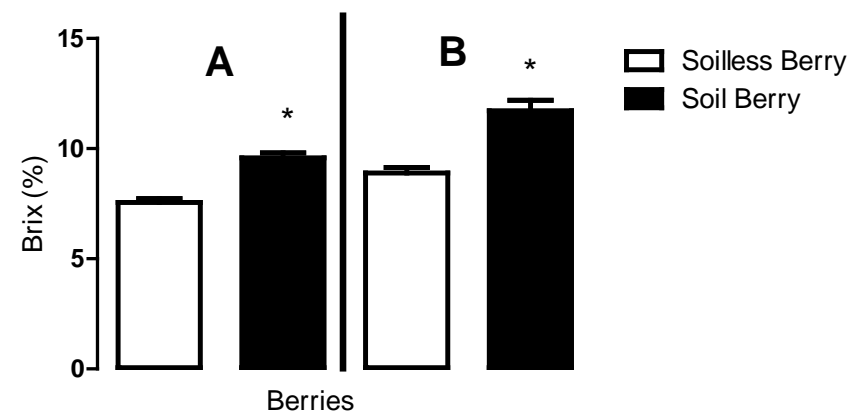

Figure 2. Brix \%. (A) Indicates soil-grown and soilless-grown strawberries; (B) Indicates soil-grown and soilless-grown raspberries. Star (*) indicates significant differences.

\subsection{Ascorbic Acid, $\alpha$-Tocopherol, and Total Polyphenolic Compounds}

For ascorbic acid, $\alpha$-tocopherol and total polyphenolic compounds analyzed, soilless grown strawberries were significantly higher compared to soil grown strawberries $(\mathrm{p}<0.05)$. For the raspberries, soil grown berries had higher amounts of bioactive compounds compared to the soilless grown raspberries (Table 2, Figures 3-5).

Ascorbic acid content for the soilless grown strawberries contained $74 \%$ more compared to the content found in soil grown strawberries. The soilless grown raspberries contained $14 \%$ less ascorbic acid content compared to the soil grown raspberries. The $\alpha$-tocopherol content of soilless grown strawberries was $53 \%$ higher compared to the soil grown strawberries. The soil grown ascorbic acid content of raspberries compared to the ascorbic acid content of soilless grown raspberries was a $7 \%$ higher amount but was not significant, $p>0.05$. A significant difference was observed in total polyphenolics, with soilless grown strawberries having significantly higher amounts of total polyphenolics and soilless grown raspberries having significantly less total polyphenolics. The soilless grown strawberries contained $22 \%$ higher amounts of total polyphenolic compounds compared to the soil grown strawberries. The opposite trend was seen with the raspberries. The soilless grown raspberries contained 23\% less compared to the soil grown raspberries.

\subsection{Fructose and Glucose}

Fructose and Glucose results are outlined in Table 3 and are illustrated in Figure 6 and Figure 7. The results indicated soil grown strawberries and raspberries contained significantly higher amounts of sugars compared to the soilless grown fruit. The soil grown strawberry contained $75 \%$ higher amount of fructose than the soilless grown strawberry. The soil grown raspberry contained $102 \%$ higher amount of fructose compared to the soilless grown raspberry. The soil grown strawberries contained 158\% higher amount of glucose compared to the soilless grown strawberries. The raspberries showed a similar trend with the soil grown raspberry containing $175 \%$ higher amount of glucose compared to the soilless raspberry. 


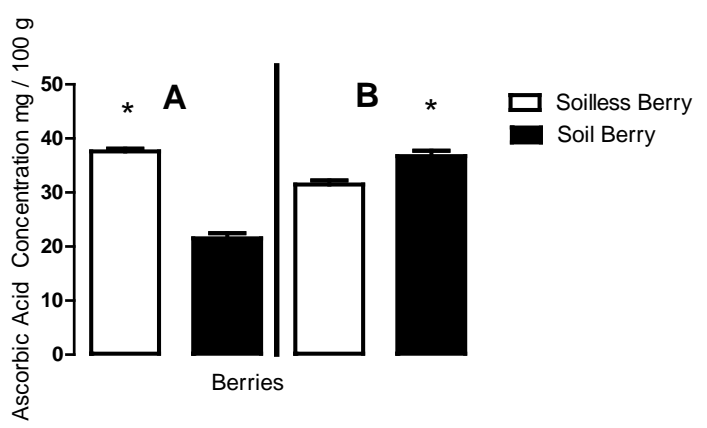

Figure 3. Ascorbic acid concentration. (A) Indicates soil-grown and soilless-grown strawberries; (B) Indicates soil-grown and soilless-grown raspberries. Open bar shows soilless-grown berries and dark bar shows soil-grown berries. Star $\left(^{*}\right)$ indicates significant differences.

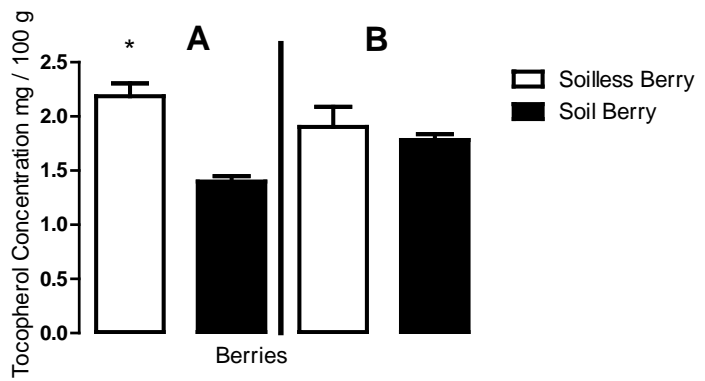

Figure 4. $\alpha$-Tocopherol concentration. (A) Indicates soil-grown and soilless-grown strawberries; (B) Indicates soil-grown and soilless-grown raspberries. Star $(*)$ indicates significant differences.

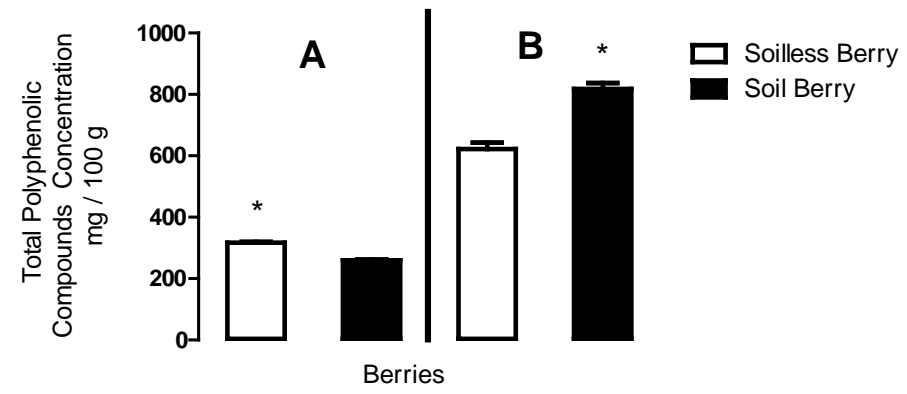

Figure 5. Total polyphenolic compound concentration. (A) Indicates soil-grown and soilless-grown strawberries; (B) Indicates soil-grown and soilless-grown raspberries. Open bar shows soilless-grown berries and dark bar shows soil-grown berries. Star $\left(^{*}\right)$ indicates significant differences.
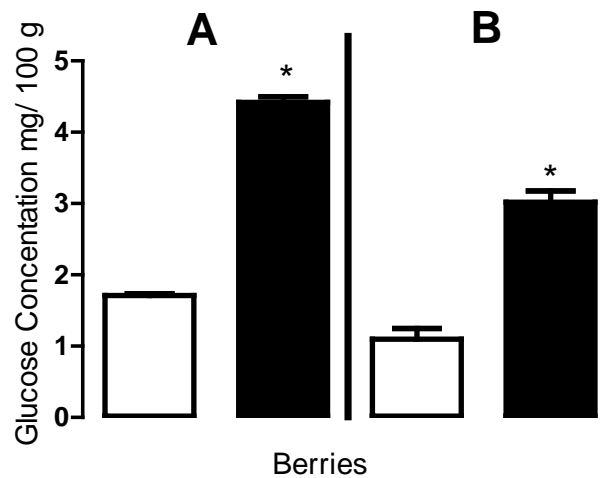

Figure 6. Glucose concentration. (A) Indicates soil-grown and soilless-grown strawberries; (B) Indicates soil-grown and soilless-grown raspberries. Star $(*)$ indicates significant differences. 


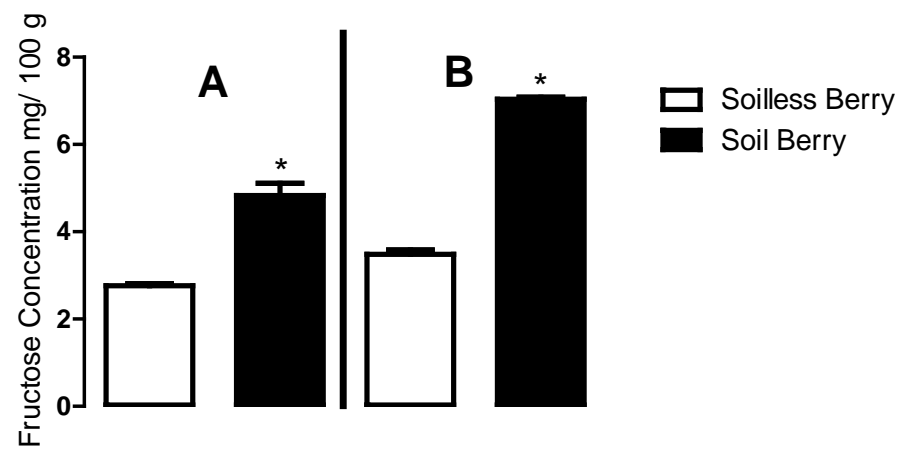

Berries

Figure 7. Fructose concentration. (A) Indicates soil-grown and soilless-grown strawberries; (B) Indicates soil-grown and soilless-grown raspberries. Star $(*)$ indicates significant differences.

Table 2. Ascorbic acid, tocopherol and total phenolic content (mg/100g) of soil and soilless berries (mean \pm SD).

\begin{tabular}{rcccc}
\hline & Soilless Strawberries & Soil Strawberries & $\mathrm{t}$ & $\mathrm{p}$ \\
\hline Ascorbic Acid & $37.62 \pm 0.49$ & $21.52 \pm 0.95$ & 15 & $<0.0001$ \\
$\alpha$-tocopherol & $2.19 \pm 0.12$ & $1.40 \pm 0.05$ & 6.05 & $<0.0001$ \\
Total phenolics & $317 \pm 2.35$ & $259 \pm 1.97$ & 18.76 & $\mathrm{p}$ \\
\hline Ascorbic Acid & Soilless Raspberries & Soil Raspberries & $\mathrm{t}$ & 0.0006 \\
--tocopherol & $31.47 \pm .074$ & $36.74 \pm 0.97$ & 4.3 & 0.53 \\
Total phenolics & $1.90 \pm 0.85$ & $1.78 \pm 0.19$ & 6.05 & $<.03$ \\
\hline
\end{tabular}

$\mathrm{N}=3$ with 3 replicates.

Table 3. Fructose and glucose content (mg/100g) of soil and soilless berries (mean \pm SD).

\begin{tabular}{rcccc}
\hline & Soilless Strawberries & Soil Strawberries & $\mathrm{t}$ & $\mathrm{p}$ \\
\hline Fructose & $2.76 \pm 0.43$ & $4.83 \pm 0.28$ & 7.29 & $<0.0001$ \\
Glucose & $1.71 \pm 0.03$ & $4.42 \pm 0.07$ & 33.1 & $<0.0001$ \\
\hline & Soilless Raspberries & Soil Raspberries & $\mathrm{t}$ & $\mathrm{p}$ \\
\hline Fructose & $3.48 \pm .096$ & $7.04 \pm 0.044$ & 33.8 & $<0.0001$ \\
\hline Glucose & $3.02 \pm 0.16$ & $1.10 \pm 0.15$ & 8.87 & $<0.0001$ \\
\hline
\end{tabular}

$\mathrm{N}=3$ with 3 replicates.

\section{Discussion}

Strawberries grown in soilless conditions have higher amounts of bioactive compounds compared to strawberries grown in soil, similar to those who compared bioactive production in produce (Buchanan \& Omaye, 2013; Claudia Kiferle, Mariella Lucchesini, Anna Mensuali-Sodi, Rita Maggini \& Pardossi, 2011; Palermo, Paradiso, De Pascale, \& Fogliano, 2012; Premuzic, Bargiela, Garcia, Rendina, \& Iorio, 1998a). However, bioactive compound contents of raspberries were equal to or greater than soil grown raspberries agreeing with others [10] [11], reiterating that the nutrient density of plants grown by soilless systems is likely highly dependent on the cultivar of interest, environmental conditions (i.e., water stress) and fertilizer bioavailability.

Differences in ascorbic acid may be due to the amount of oxidative stress the plant endures, e.g. ascorbic acid in the biologically active role as an antioxidant. Soilless systems optimize growing conditions, therefore, soilless grown plants are less likely to undergo oxidative stress endured by environmental causes [33]. Ascorbic acid and 
$\alpha$-tocopherol work together for antioxidant protection. When tocopherol is oxidized to the tocopheroxyl radical, ascorbic acid can donate electrons to rejuvenate $\alpha$-tocopherol. Because of the interaction between ascorbic acid and tocopherol, concentration changes in one should be reflective of concentration changes in the other. Lighting (i.e., shading) and fertilizer application can affect ascorbic acid production in plants. Ascorbic acid is created during photosynthesis, however, both of our plant growing systems had the same exposure to light therefore it is more likely the causes were induced by differences in nutrient content. Soilless and soil grown systems are fundamentally different, with soilless having more nutrients bioavailable to the plants all the time.

In agreement with our findings previous research has expressed higher rates of fertilizer increased ascorbic production at the expense of decreasing carbohydrates in the plants [34]. In our soilless system, strawberries, had significantly higher amounts of ascorbic acid but lower amounts of fructose and glucose $(p<0.05)$. Another possible reason for the lower sugar content in the soilless plants compared to soil plants is the potential for higher osmotic pressure in soil plants, increasing the sugar content of the plants. This can commonly occur when plants are drought stressed since plant survival largely depends on carbohydrates [13]. Although our plants were never intentionally drought stressed, it is possible that compared to the soilless plants, which were continuously immersed in water, they may have endured some degree of drought stress with being watered three times weekly. Previous research has indicated a relationship to fertilization and nutritional outcomes in the crop [35]-[39]. Both soil and soilless fertilization concentration was checked using portable ppm meters. The average of the soilless grown strawberries averaged around $400 \mathrm{ppm}$, and the soil grown plants averaged around $600 \mathrm{ppm}$. The soilless grown raspberries averaged about $500 \mathrm{ppm}$ and the soil grown plants averaged about $600 \mathrm{ppm}$, which may influence the differences in nutritional variation within the produce.

\section{Conclusion}

Other research has shown a difference between soilless growing systems and nutritional content of the plant [40]. In order to optimize plant production as well as provide a nutrient dense crop, more research should be conducted to determine the best methods for strawberry and raspberry production. Further research should evaluate feasibility as well as nutritional value of soilless raspberries. We have seen that soilless strawberries have the potential to provide a superior nutrient dense crop compared to soil grown plants. The soilless system has many environmental benefits to provide sustainable food in arid or urban regions. This, added with superior nutrition quality, may contribute significantly to environmental and public health issues that we are currently facing.

\section{Acknowledgements}

We thank Eric Horton for greenhouse technical and maintenance assistance. We thank Kevin Hong for laboratory assistance. We acknowledge the Nevada Agricultural Experiment Station, University of Nevada, Reno for the support of this study. HATCH \#0745. The research was done and reported to partially fulfill dissertation requirement of C. Treftz.

\section{References}

[1] Agriculture, USDA (2015) Food Deserts. Create Access to Healthy Affordable Food, 1.

[2] Steinmetz, K.A. and Potter, J.D. (1996) Vegetables, Fruit, and Cancer Prevention: A Review. Journal of the American Dietetic Association, 96, 1027-1039. http://dx.doi.org/10.1016/S0002-8223(96)00273-8

[3] Blasa, M., Gennari, L., Angelino, D. and Ninfali, P. (2010) Fruit and Vegetable Antioxidants in Health. In: Bioactive Foods in Promoting Health: Fruits and Vegetables, Academic Press, San Diego, 37-58. http://dx.doi.org/10.1016/b978-0-12-374628-3.00003-7

[4] Resh, H.M. and Howard, M. (2002) Hydroponic Food Production: A Definitive Guidebook for the Advanced Home Gardener and the Commercial Hydroponic Grower. EUA, St. Bárbara.

[5] Glanz, K., Basil, M., Maibach, E., Goldberg, J. and Snyder, D. (1998) Why Americans Eat What They Do: Taste, Nutrition, Cost, Convenience, and Weight Control Concerns as Influences on Food Consumption. Journal of the American Dietetic Association, 98, 1118-1126. http://dx.doi.org/10.1016/S0002-8223(98)00260-0

[6] Buchanan, D.N. and Omaye, S.T. (2013) Comparative Study of Ascorbic Acid and Tocopherol Concentrations in Hydroponic- and Soil-Grown Lettuces. Food and Nutrition Sciences, 4, 1047-1053. http://dx.doi.org/10.4236/fns.2013.410136

[7] Palermo, M., Paradiso, R., De Pascale, S. and Fogliano, V. (2012) Hydroponic Cultivation Improves the Nutritional 
Quality of Soybean and Its Products. Journal of Agricultural and Food Chemistry, 60, 250-255. http://dx.doi.org/10.1021/jf203275m

[8] Premuzic, Z., Bargiela, M., Garcia, A., Rendina, A. and Iorio, A. (1998) Calcium, Iron, Potassium, Phosphorus, and Vitamin C Content of Organic and Hydroponic Tomatoes. HortScience, 33, 255-257.

[9] Kiferle, C., Lucchesini, M., Mensuali-Sodi, A., Maggini, R., Raffaelli, A. and Pardossi1, A. (2011) Rosmarinic Acid Content in Basil Plants Grown in Vitro and in Hydroponics. Central European Journal of Biology, 6, 946-957. http://dx.doi.org/10.2478/s11535-011-0057-1

[10] Kimura, M. and Rodriguez-Amaya, D.B. (2003) Carotenoid Composition of Hydroponic Leafy Vegetables. Journal of Agricultural and Food Chemistry, 51, 2603-2607. http://dx.doi.org/10.1021/jf020539b

[11] Selma, M.V., Luna, M.C., Martínez-Sánchez, A., Tudela, J.A., Beltrán, D., Baixauli, C. and Gil, M.I. (2012) Sensory Quality, Bioactive Constituents and Microbiological Quality of Green and Red Fresh-Cut Lettuces (Lactuca sativa L.) Are Influenced by Soil and Soilless Agricultural Production Systems. Postharvest Biology and Technology, 63, 16-24. http://dx.doi.org/10.1016/j.postharvbio.2011.08.002

[12] Gruda, N. (2005) Impact of Environmental Factors on Product Quality of Greenhouse Vegetables for Fresh Consumption. Critical Reviews in Plant Sciences, 24, 227-247.

[13] Brestic, M. and Zivcak, M. (2013) PSII Fluorescence Techniques for Measurement of Drought and High Temperature Stress Signal in Crop Plants: Protocols and Applications. In: Rout, G.R. and Das Bandhu, A., Eds., Molecular Stress Physiology of Plants, Springer India, New Delhi, 87-131. http://dx.doi.org/10.1007/978-81-322-0807-5

[14] Gruda, N. (2009) Do Soilless Culture Systems Have an Influence on Product Quality of Vegetables ? Journal of Applied Botany and Food Quality, 82, 141-147.

[15] Meyers, K.J., Watkins, C.B., Pritts, M.P. and Liu, R.H. (2003) Antioxidant and Antiproliferative Activities of Strawberries. Journal of Agricultural and Food Chemistry, 51, 6887-6892. http://dx.doi.org/10.1021/jf034506n

[16] Hannum, S.M. (2004) Potential Impact of Strawberries on Human Health: A Review of the Science. Critical Reviews in Food Science and Nutrition, 44, 1-17. http://dx.doi.org/10.1080/10408690490263756

[17] Liu, M., Li, X.Q., Weber, C., Lee, C.Y., Brown, J. and Liu, R.H. (2002) Antioxidant and Antiproliferative Activities of Raspberries. Journal of Agricultural and Food Chemistry, 50, 2926-2930. http://dx.doi.org/10.1021/jf0111209

[18] Combs, G.F. (2008) The Vitamins: Fundamental Aspects in Nutrition and Health. Elsevier B.V., Burlington.

[19] Zhang, Y., Seeram, N.P., Lee, R., Feng, L. and Heber, D. (2008) Isolation and Identification of Strawberry Phenolics with Antioxidant and Human Cancer Cell Antiproliferative Properties. Journal of Agricultural and Food Chemistry, 56, 670-675. http://dx.doi.org/10.1021/jf071989c

[20] US Department of Agriculture, Agricultural Research Service (2011) USDA National Nutrient Database for Standard Reference, Release 24.

[21] Crisosto, C.H., Crisosto, G. and Neri, F. (2006) Understanding Tree Fruit Quality Based on Consumer Acceptance. Acta Horticulturae, 712, 183-189.

[22] Zude, M., Herold, B., Roger, J.M., Bellon-Maurel, V. and Landahl, S. (2006) Non-Destructive Tests on the Prediction of Apple Fruit Flesh Firmness and Soluble Solids Content on Tree and in Shelf Life. Journal of Food Engineering, 77, 254-260. http://dx.doi.org/10.1016/j.jfoodeng.2005.06.027

[23] USDA (2013) Technical Procedures Manual.

[24] AOAC (1998) Official Methods of Analysis of AOAC International. Association of Official Analytical Chemists International, CD-ROM.

[25] Omaye, S.T., Turnbull, J.D. and Sauberlich, H.E. (1979) Selected Methods for the Determination of Ascorbic Acid in Animal Cells, Tissues, and Fluids. Methods in Enzymology, 62, 3-11. http://dx.doi.org/10.1016/0076-6879(79)62181-x

[26] Duygu Ozsoy, H. and Van Leeuwen, J. (2010) Removal of Color from Fruit Candy Waste by Activated Carbon Adsorption. Journal of Food Engineering, 101, 106-112. http://dx.doi.org/10.1016/j.jfoodeng.2010.06.018

[27] Kahn, M.M., Rahman, M.M., Islam, S. and Begum, S. (2006) A Simple UV-Spectrophotometric Method for the Determination of Vitamin C Content in Various Fruits and Vegetables at Sylhet Area in Bangladesh. Journal of Biological Sciences, 6, 388-392. http://dx.doi.org/10.3923/jbs.2006.388.392

[28] Fabianek, J., Apak, E., Gunaydi, E. and Sogen, K. (1968) Micromethod for Tocopherol Determination in Blood Serum. Clinical Chemistry, 14, 456-462.

[29] Heinonen, I., Lehtonen, P. and Hopia, A. (1998) Antioxidant Activity of Berry and Fruit Wines and Liquors. Journal of Agricultural and Food Chemistry, 46, 25-31. http://dx.doi.org/10.1021/jf970489o

[30] Marinova, D., Ribarova, F. and Atanassova, M. (2005) Total Phenolics and Total Flavonoids in Bulgarian Fruits and Vegetables. Journal of Chemical Technology and Metallurgy, 40, 255-260. 
[31] Taylor, K.A.C.C. (1995) A Colorimetric Fructose Assay. Applied Biochemistry and Biotechnology, 53, 215-227. http://dx.doi.org/10.1007/BF02783497

[32] Miller, G.L. (1959) Use of Dinitrosalicyclic Reagent for Determination of Reducing Sugar. Analytical Chemistry, 31, 426-428. http://dx.doi.org/10.1021/ac60147a030

[33] Sgherri, C., Cecconami, S., Pinzino, C., Navari-Izzo, F. and Izzo, R. (2010) Levels of Antioxidants and Nutraceuticals in Basil Grown in Hydroponics and Soil. Food Chemistry, 123, 416-422. http://dx.doi.org/10.1016/j.foodchem.2010.04.058

[34] Premuzic, Z., Bargiela, M., Garcia, A., Rendina, A. and Iorio, A. (1998) Calcium, Iron, Potassium, Phosphorus, and Vitamin C Content of Organic and Hydroponic Tomatoes. HortScience, 33, 255-257.

[35] Elia, A., Santamaria, P. and Serio, F. (1998) Nitrogen Nutrition, Yield and Quality of Spinach. Journal of the Science of Food and Agriculture, 76, 341-346.

[36] Konstantopoulou, E., Kapotis, G., Salachas, G., Petropoulos, S.A., Karapanos, I.C. and Passam, H.C. (2010) Nutritional Quality of Greenhouse Lettuce at Harvest and after Storage in Relation to N Application and Cultivation Season. Scientia Horticulturae, 125, 93.e1-93.e5. http://dx.doi.org/10.1016/j.scienta.2010.03.003

[37] Zhang, Y. (2005) Effects of Nitrogen Supply on Nutritional Quality and Antioxidative Enzyme Activities of Spinach. Chinese Journal of Applied Ecology, 16, 519-523.

[38] Randle, W.M. (2000) Increasing Nitrogen Concentration in Hydroponic Solutions Affects Onion Flavor and Bulb Quality. Journal of the American Society for Horticultural Science, 125, 254-259.

[39] Sun, Y.D., Luo, W.R. and Liu, H.C. (2014) Effects of Different Nitrogen Forms on the Nutritional Quality and Physiological Characteristics of Chinese Chive Seedlings. Plant, Soil and Environment, 60, 216-220.

[40] Gichuhi, P.N., Mortley, D., Bromfield, E. and Bovell-Benjamin, A.C. (2009) Nutritional, Physical, and Sensory Evaluation of Hydroponic Carrots (Daucus carota L.) from Different Nutrient Delivery Systems. Journal of Food Science, 74, S403-S412. http://dx.doi.org/10.1111/j.1750-3841.2009.01338.x 